\title{
Mate Tea Prevents Oxidative Stress in the Blood and Hippocampus of Rats with Acute or Chronic Ethanol Administration
}

\author{
Bianca Scolaro, ${ }^{1}$ Daniela Delwing-de Lima, ${ }^{2}$ \\ José Geraldo Pereira da Cruz, ${ }^{1}$ and Débora Delwing-Dal Magro ${ }^{1}$ \\ ${ }^{1}$ Centro de Ciências Exatas e Naturais, Departamento de Ciências Naturais, Universidade Regional de Blumenau, \\ Rua Antônio da Veiga 140, 89012-900 Blumenau, SC, Brazil \\ ${ }^{2}$ Departamento de Medicina, Universidade da Região de Joinville (UNIVILLE), Campus Universitário, Bairro Bom Retiro, \\ 89201-972 Joinville, SC, Brazil \\ Correspondence should be addressed to Débora Delwing-Dal Magro, deboradelwing@furb.br
}

Received 13 October 2011; Revised 12 December 2011; Accepted 28 December 2011

Academic Editor: Cristina Angeloni

Copyright (๑) 2012 Bianca Scolaro et al. This is an open access article distributed under the Creative Commons Attribution License, which permits unrestricted use, distribution, and reproduction in any medium, provided the original work is properly cited.

\begin{abstract}
Objective. The aim of this study was to evaluate the influence of acute and chronic intake of mate tea on the effects elicited by acute and chronic administration of ethanol. Methods. Oxidative stress was evaluated by measuring thiobarbituric acid-reactive substances (TBARS), as well as the activities of the antioxidant enzymes, catalase (CAT), glutathione peroxidase (GSH-Px), and superoxide dismutase (SOD) in the hippocampus and blood of rats. Male Wistar rats were randomly assigned to four groups, for both acute and chronic treatment: (1) control group, (2) treated group, (3) intoxicated group, (4) and intoxicated group treated with mate tea. Results. Both ethanol administrations significantly increased TBARS in plasma and hippocampus of rats and altered antioxidant enzyme activities, changes which were reverted by mate tea administration. Conclusions. Data indicate that acute and chronic ethanol administration induced oxidative stress in hippocampus and blood and that mate tea treatment was able to prevent this situation.
\end{abstract}

\section{Introduction}

The cellular metabolism of all aerobic organisms produces reactive oxygen species (ROS), which are neutralized by nonenzymatic defenses ( $\alpha$-tocopherol, carotene, ascorbic acid, etc.) and the activity of antioxidant enzymes. The imbalance between the production and the elimination of ROS represents a situation named oxidative stress characterized by molecular injuries induced by oxidative reactions with proteins, carbohydrates, and lipids [1]. The lipid content of the cellular membrane is the first structure to be attacked by ROS and, thus, lipid peroxidation represents the most frequent injury resulting from the action of ROS [2].

ROS have been associated with the physiopathology of several diseases, such as cellular dysfunction of patients with atherogenesis, cardiopathy, senility, carcinogenesis, rheumatic disease, and diabetes type 2 , and are also responsible for the ageing process $[3,4]$. Moreover, ROS are involved in the pathogenesis of neurologic conditions such as epilepsy, multiple sclerosis, dementia, and neurodegenerative diseases such as Alzheimer and Parkinson. This is understandable since the central nervous system (CNS) is highly sensitive to oxidative stress because of its high oxygen consumption, its high iron and lipid contents, especially polyunsaturated fatty acids, and the low activity of its antioxidant defenses [5-7].

Much evidence indicates that antioxidant ability decreases with ageing, leading to the increase of macromolecule oxidation and, consequently, related diseases [8-11]. The cellular redox state might be modified by the diet, since food components can increase or decrease antioxidant cellular ability. Chronic ethanol intoxication, for example, may lead to a high generation of ROS, while the consumption of dietary antioxidants contributes to the enhancement of the 
endogenous mechanisms of defense (enzymatic antioxidant system) $[12,13]$. In literature, there are several strategies for induction of oxidative stress; in this work we used the experimental model described by Kasdallah-Grissa et al. [14], which consists in an intraperitoneal injection of 35\% ethanol at a dose of $3 \mathrm{~g} / \mathrm{kg}$.

There are many ways by which the diet may interfere in the formation and defense against free radicals [1517]. Fruits, vegetables, and whole grains possess significant amounts of bioactive phytochemicals capable of promoting great health benefits, beyond basic nutrition [18]. Other natural antioxidants sources include teas, since their consumption may represent a safe alternative to increase the ingestion of dietetic antioxidants. Tea is the second most consumed beverage in the world, with a per capita human ingestion of approximately $120 \mathrm{~mL} /$ day [19]. In this context, the aqueous extract of yerba mate (Ilex paraguariensis) is consumed at a rate of over 1 liter per day by millions of individuals in South America, representing the mainly alternative to coffee and tea [20].

Ilex paraguariensis infusion is a potential source of polyphenols. Its aqueous extract is a typical antioxidant-containing beverage that is largely consumed in several South American countries, including Southern Brazil, Uruguay, Paraguay, and Argentina. Moreover, yerba mate presents a healthy nutritional profile, containing the vitamins $\mathrm{A}, \mathrm{C}$, and E; B complex; the minerals potassium, magnesium, calcium, manganese, iron, selenium, phosphorus, and zinc; several aminoacids; various polyphenols, mainly caffeoyl derivatives (such as chlorogenic acid); and some flavonoids (rutin, quercetin, kaempferol) [21].

Polyphenols are a class of compounds containing a benzene ring bound with one or more hydroxyl groups which exert antioxidant activity [22]. Consumption of mate tea significantly contributes to the overall antioxidant intake and provides high amounts of caffeoylquinic acid derivatives, with biological effects potentially beneficial for human health. The compound that may be primarily responsible for this activity is chlorogenic acid [23]. Chlorogenic acids are a family of esters formed between certain trans cinnamic acids and (-)-quinic acid and are also major phenolics compounds in coffee, strawberries, pineapples, apples, sunflower, and blueberries. Chlorogenic acids are free radical and metal scavengers, may interfere with glucose absorption, and have been shown to modulate gene expression of antioxidant enzymes, among other biological activities [24]. Roasted extracts of Ilex paraguariensis keep the same components with the addition of melanoidins, which have some bioactive properties of their own [21].

Reports that demonstrate the ability of antioxidant nutrients to revert or prevent conditions initiated by the increased production of free radicals are extremely important to promote healthy food habits, combating NTCD and even precocious ageing through the diet. As such, this study evaluated the effects of acute and chronic ethanol administration on an important parameter of oxidative stress, namely, thiobarbituric acid-reactive substances (TBARS), as well as on the activities of the antioxidant enzymes catalase (CAT), glutathione peroxidase (GSH-Px), and superoxide dismutase (SOD) in the blood and hippocampus of rats and the influence of acute and chronic intake of mate tea, a product derived from yerba mate, on the effects elicited by acute and chronic administration of ethanol on these parameters. We used hippocampus because the brain is exceptionally susceptible to oxidative stress $[6,7]$ that may be caused by xenobiotics such as ethanol. In addition, after ethanol intoxication, an increase in the level of aldehydes is observed in the brain as well as the serum of rats [25] and aldehyde oxidation by some chemicals and enzymatic systems leads to the generation of free radicals [26].

\section{Methods and Materials}

2.1. Animals. Wistar rats of 60 and 45 days of age (180$200 \mathrm{~g}$ ), obtained from the Central Animal House of the Regional University of Blumenau, Blumenau, Brazil, were used in the experiments. The animals from our own breeding stock were maintained on a $12 \mathrm{~h}$ light/12 $\mathrm{h}$ dark cycle at a constant temperature $\left(22 \pm 1^{\circ} \mathrm{C}\right)$, with free access to water and commercial protein chow. The "Principles of Laboratory Animal Care" (NIH publication 85-23, revised 1985) were followed in all the experiments and the experimental protocol was approved by the Ethics Committee for Animal Research of the local Institution. All chemicals were purchased from Sigma Chemical Co., St. Louis, MO, USA.

2.2. Mate Tea Preparation. Mate tea used in this study was from the same batch and was obtained from Leão Jr., Curitiba, PR, Brazil. The tea beverage was prepared accordingly to the instructions of the label.

2.3. Acute Treatment of Ethanol and Mate Tea. Twenty male rats aged 60 days were randomly assigned to four groups, according to the intervention: (1) control group received a single intraperitoneal injection of $0.9 \% \mathrm{NaCl}$ and pure water by intragastric gavage; (2) treated group received a dose of mate tea $(0.5 \mathrm{~g} / \mathrm{kg})$ [27] by intragastric gavage and an intraperitoneal injection of $0.9 \% \mathrm{NaCl}$; (3) intoxicated group received intraperitoneal injection of $35 \%$ ethanol at a dose of $3 \mathrm{~g} / \mathrm{kg}$ [14] and pure water by intragastric gavage; (4) intoxicated group treated with mate tea received a dose of mate tea $(0.5 \mathrm{~g} / \mathrm{kg})$ [27] by intragastric gavage and intraperitoneal injection of $35 \%$ ethanol at a dose of $3 \mathrm{~g} / \mathrm{kg}$ [14]. The mate tea dose used was equivalent to that found in 0.75 liters mate tea/day [13]. Animals were sacrificed by decapitation without anaesthesia $1 \mathrm{~h}$ later, and the hippocampus removed and blood collected.

2.4. Chronic Treatment of Ethanol and Mate Tea. Twenty male rats aged 45 days were randomly assigned to four groups, according to the intervention, as described previously for the acute treatment. Each group received the respective intervention daily, for 15 days. Animals were sacrificed by decapitation without anaesthesia 12 hours after the last administration, and the brain removed and blood collected. 
2.5. Preparation of Brain Tissue. Animals were killed by decapitation and the hippocampus was removed and dissected immediately on an ice-cooled glass plate. Time elapsed between decapitation and dissection was less than $1 \mathrm{~min}$. After dissection, the hippocampus was homogenized with appropriate buffer for each assay with a Potter-Elvehjem glass homogenizer. The maximum period between homogenate preparation and enzyme analysis was always less than 3 days. All procedures were carried out at $0-4^{\circ} \mathrm{C}$.

2.6. Erythrocyte and Plasma Preparation. Erythrocytes and plasma were prepared from whole blood samples obtained from rats. Whole blood was collected and transferred to heparinized tubes for erythrocyte separation. Blood samples were centrifuged at $1,000 \times \mathrm{g}$, and plasma was removed by aspiration and frozen at $-80^{\circ} \mathrm{C}$ until determination. Erythrocytes were washed three times with cold saline solution $(0.153 \mathrm{~mol} / \mathrm{L}$ sodium chloride). Lysates were prepared by the addition of $1 \mathrm{~mL}$ of distilled water to $100 \mu \mathrm{L}$ of washed erythrocytes and frozen at $-80^{\circ} \mathrm{C}$ until determination of the antioxidant enzyme activities.

For antioxidant enzyme activity determination, erythrocytes were frozen and thawed three times and centrifuged at $13,500 \times \mathrm{g}$ for $10 \mathrm{~min}$. The supernatant was diluted in order to contain approximately $0.5 \mathrm{mg} / \mathrm{mL}$ of protein.

2.7. Thiobarbituric Acid Reactive Substances (TBARS). TBARS measure malondialdehyde (MDA), a product of lipoperoxidation caused mainly by hydroxyl free radicals. For measurements, homogenates and plasma in $1.15 \% \mathrm{KCl}$ were mixed with $20 \%$ trichloroacetic acid and $0.8 \%$ thiobarbituric acid and heated in a boiling water bath for $60 \mathrm{~min}$. TBARS were determined by the absorbance at $535 \mathrm{~nm}$. A calibration curve was performed using 1,1,3,3-tetramethoxypropane and each curve point was subjected to the same treatment as that of the supernatants. TBARS were calculated as nanomole of malondialdehyde formed per milligram of protein [28].

2.8. Catalase Activity Assay (CAT). Hydrogen peroxide $\left(\mathrm{H}_{2} \mathrm{O}_{2}\right)$ disappearance was continuously monitored with a spectrophotometer at $240 \mathrm{~nm}$ for $90 \mathrm{~s}$. One unit of the enzyme is defined as $1 \mu \mathrm{mol}$ of hydrogen peroxide consumed per minute, and the specific activity is reported as units per mg protein [29].

2.9. Glutathione Peroxidase Activity Assay (GSH-Px). GSH$\mathrm{Px}$ activity was measured by the method of Wendel [30], except for the concentration of nicotinamide adenine dinucleotide phosphate (NADPH), which was adjusted to $0.1 \mathrm{mM}$ after previous tests performed in our laboratory. Tert-butylhydroperoxide was used as substrate. NADPH disappearance was continuously monitored with a spectrophotometer at $340 \mathrm{~nm}$ for $4 \mathrm{~min}$. One GSH-Px unit is defined as $1 \mu \mathrm{mol}$ of NADPH consumed per minute, and specific activity is reported as units per mg protein.

2.10. Superoxide Dismutase Assay (SOD). This method for the assay of SOD activity is based on the capacity of pyrogallol to autoxidize, a process highly dependent on oxygen
$\left(\mathrm{O}_{2}\right)$, which is a substrate for SOD [31]. The inhibition of autoxidation of this compound occurs in the presence of SOD, whose activity can then be indirectly assayed spectrophotometrically at $420 \mathrm{~nm}$. A calibration curve was performed with purified SOD as standard, in order to calculate the activity of SOD present in the samples. The results were reported as units/mg protein.

2.11. Protein Determination. Protein was measured by the method of Lowry et al. with bovine serum albumin used as standard [32].

2.12. Statistical Analysis. Data were analyzed by Student's $t$ test and by analysis of variance (ANOVA) followed by the Duncan multiple range tests when the $F$-test was significant. All analyses were performed using the Statistical Package for the Social Sciences (SPSS) software in a PC-compatible computer. $P<0.05$ was considered significant.

\section{Results}

We first studied the effects of acute ethanol, mate tea, and mate tea plus ethanol administration on an important parameter of lipoperoxidation, namely, TBARS and on the antioxidant enzymes activities of CAT, GSH-Px, and SOD in the hippocampus and blood of rats. Figure 1 shows that acute ethanol administration significantly increased TBARS (81\%) (a) as well as decreased CAT (40\%) (b) and SOD (40\%) (c) activities in the hippocampus of rats and that acute mate tea administration prevented the increase in TBARS $(F(3,16)=$ 12.895; $P<0.001)$, as well as the reduction of CAT $(F(3,16)=4.795 ; P<0.01)$ and $\operatorname{SOD}(F(3,16)=11.825$; $P<0.001)$ activity, caused by acute ethanol administration, when compared to the control group. However acute ethanol administration had no effect on GSH-Px $(t(8)=0.490 ; P>$ 0.05 ) activity, when compared to the control group (result not shown). As can be observed in Figure 2, acute ethanol administration significantly increased TBARS levels (35\%) (a) and CAT (61\%) (b) activity in plasma and erythrocytes of rats, respectively, while acute mate tea administration was able to prevent the increase in TBARS $(F(3,16)=$ 11.898; $P<0.001)$, caused by ethanol, in the plasma of rats. In contrast, such prevention was not observed for the increased CAT activity observed in the erythrocytes of rats $(F(3,16)=5.809 ; P<0.01)$. In addition, GSH-Px $(t(8)=0.60 ; P>0.05)$ and $\operatorname{SOD}(t(8)=-1.714 ; P>$ 0.05 ) activities did not undergo any significant alteration by acute ethanol administration, when compared to the control groups (results not shown).

Subsequently, the effects of chronic ethanol, mate tea, and mate tea plus ethanol administration on TBARS and on the antioxidant enzymes activities of CAT, GSH-Px, and SOD were also evaluated in the hippocampus and plasma/erythrocytes of rats. As can be observed, Figure 3 shows that chronic ethanol administration significantly increased TBARS (48\%) (a) and decreased CAT (21\%) (b) and GSH-Px (8\%) (c) activities in the hippocampus of rats and that mate tea pretreatment prevented the increase in TBARS $(F(3,16)=10.958 ; P<0.001)$, as well as the 


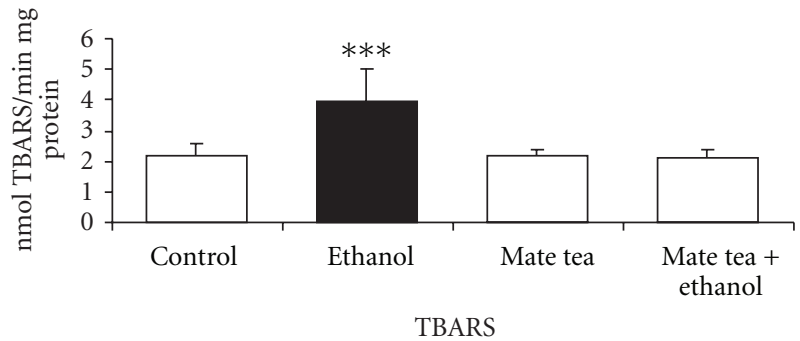

(a)

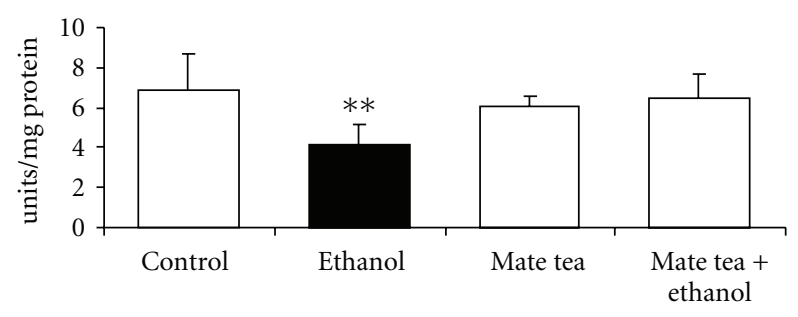

CAT

(b)

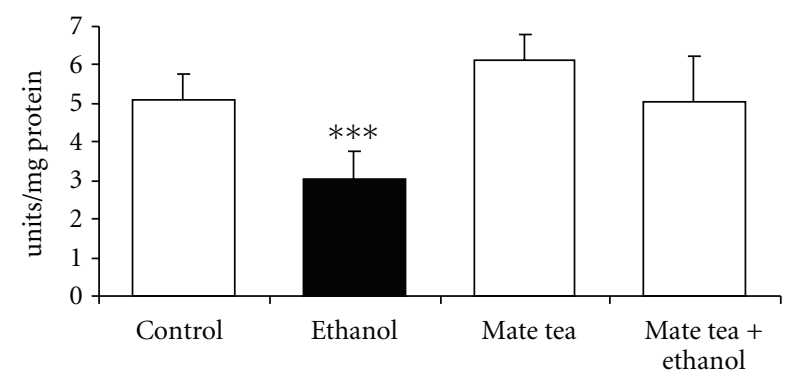

SOD

(c)

FIGURE 1: Effects of acute administration of ethanol, mate tea, and mate tea plus ethanol on thiobarbituric acid reactive substances (TBA-RSs) (a), on catalase (b) and superoxide dismutase (c) activities in rat hippocampus. Data are mean \pm SD for 5 independent experiments (animals) performed in duplicate. ${ }^{* *} P<0.01$; ${ }^{* * *} P<$ 0.001 compared to control group (Duncan multiple-range test). One catalase (CAT) unit is defined as $1 \mu \mathrm{mol}$ of $\mathrm{H}_{2} \mathrm{O}_{2}$ consumed per minute. One superoxide dismutase (SOD) unit is defined as the amount of SOD necessary to inhibit $50 \%$ of pyrogallol autoxidation.

decrease in CAT $(F(3,16)=3.247 ; P<0.05)$ and GSH$\operatorname{PX}(F(3,16)=4.882 ; P<0.01)$ activities in the rat hippocampus. SOD $(t(8)=1.471 ; P>0.05)$ activity did not undergo any significant changes by chronic ethanol administration (result not shown). With regard to the chronic ethanol, mate tea and mate tea plus ethanol administration in the plasma/erythrocytes of rats, Figure 4 shows that chronic ethanol administration significantly increased TBARS (52\%) (a) and SOD (38\%) (b) activity as well as decreased CAT (42\%) (c) and GSH-PX (13\%) (d) activities in blood of rats. In addition, pretreatment with mate tea prevented the increase in TBARS $(F(3,16)=9.043 ; P<0.001)$ in the plasma of rats, prevented the increase in $\operatorname{SOD}(F(3,16)=$ 9.032; $P<0.001)$ activity in erythrocytes, and also abolished

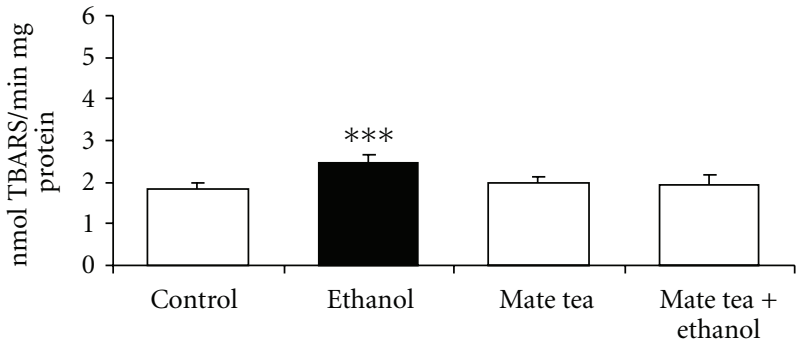

TBARS

(a)

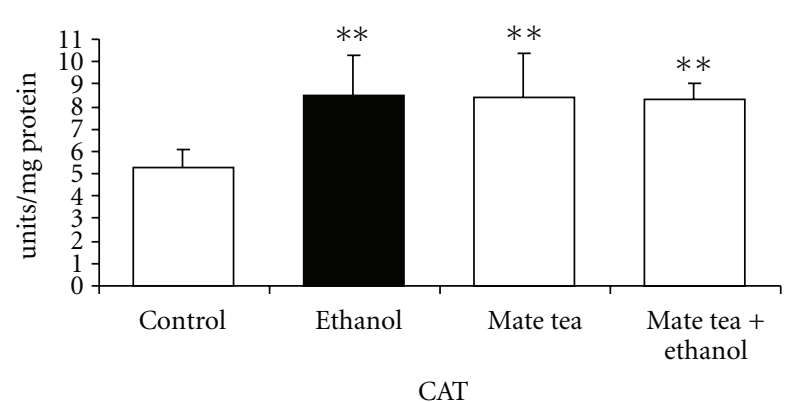

(b)

FIGURE 2: Effects of acute administration of ethanol, mate tea, and mate tea plus ethanol on thiobarbituric acid reactive substances (TBA-RSs) (a) and on catalase (b) activity in rat blood. Data are mean \pm SD for 5 independent experiments (animals) performed in duplicate. ${ }^{* *} P<0.01 ;{ }^{* * *} P<0.001$ compared to control group (Duncan multiple-range test). One catalase (CAT) unit is defined as $1 \mu \mathrm{mol}$ of $\mathrm{H}_{2} \mathrm{O}_{2}$ consumed per minute.

the reductions in $\operatorname{CAT}(F(3,16)=10.261 ; P<0.001)$ and GSH-Px $(F(3,16)=28.783 ; P<0.01)$ activities in erythrocytes, caused by chronic ethanol administration, respectively. Statistical analyses demonstrated that acute and chronic mate tea administration per se did not interfere in most of the parameters studied.

\section{Discussion}

Growing evidence suggests that the major killers, cardiovascular disease and cancer, can be prevented or delayed to some extent by dietary changes, such as a reduction in fat intake and increased consumption of fruits, grains, and vegetables [33-35]. We obtain several compounds from a healthy diet that may act to diminish oxidative damage in vivo. Since our endogenous antioxidant defenses are not 100\% efficient, it is reasonable to propose that dietary antioxidants are important in diminishing the cumulative effects of oxidative damage over the long human lifespan, and that they account for some of the beneficial effects of fruits, grains, and vegetables [36].

In this study, we verified the effects of acute and chronic ethanol, mate tea, and mate tea plus ethanol administration on TBARS and on the antioxidant enzymes activities of CAT, GSH-Px, and SOD in the hippocampus and blood of rats, in order to verify whether the dose chosen of ethanol 


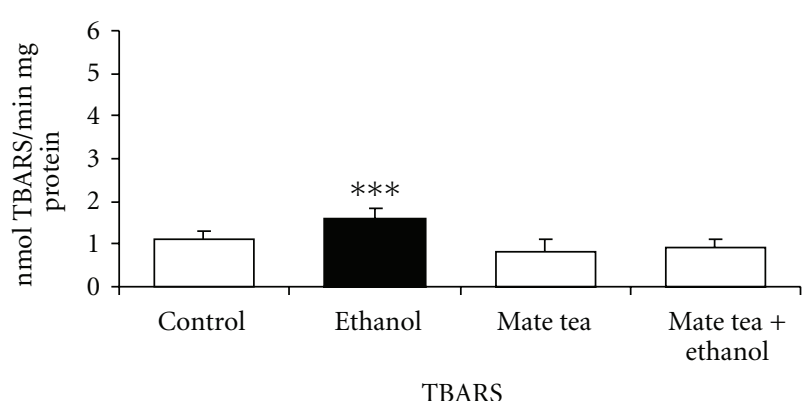

(a)

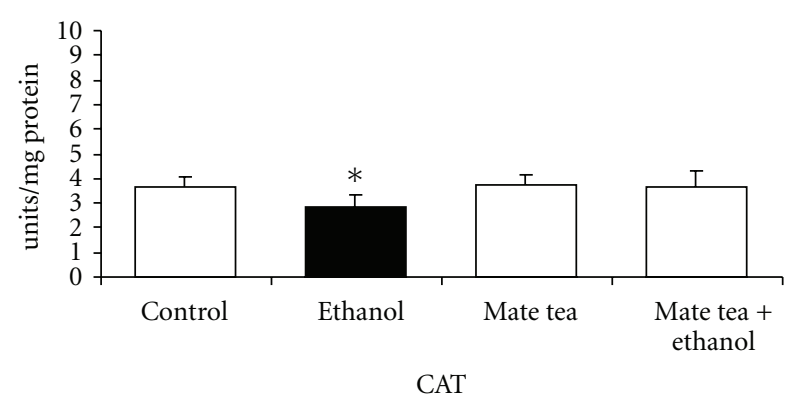

(b)

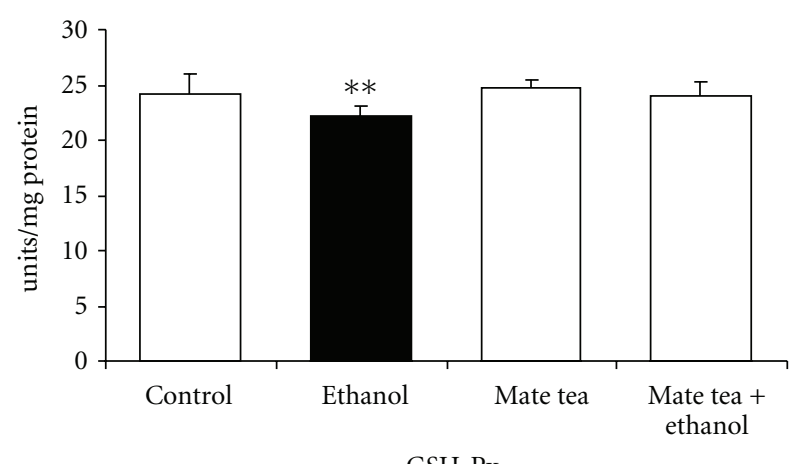

GSH-Px

(c)

FIGURE 3: Effects of chronic administration of ethanol, mate tea, and mate tea plus ethanol on thiobarbituric acid reactive substances (TBA-RSs) (a), on catalase (b) and glutathione peroxidase (c) activities in rat hippocampus. Data are mean \pm SD for 5 independent experiments (animals) performed in duplicate. ${ }^{*} P<0.05$; ${ }^{* *} P<$ $0.01 ;{ }^{* * *} P<0.001$ compared to control group (Duncan multiplerange test). One catalase (CAT) unit is defined as $1 \mu \mathrm{mol}$ of $\mathrm{H}_{2} \mathrm{O}_{2}$ consumed per minute. One glutathione peroxidase (GSH-Px) unit is defined as $1 \mu \mathrm{mol}$ of NADPH consumed per minute.

could induce oxidative stress and the possible antioxidant properties of mate tea, since yerba mate possesses many bioactive compounds, such as caffeine, phenolic acids, and saponins, which are absorbed by the body and may act as antioxidants, and since mate tea is a product derived from this herb.

Our results showed that acute and chronic ethanol administration provoked an oxidative stress, as demonstrated by the elevated TBARS levels in the hippocampus and plasma of rats. With regard to antioxidant enzyme activities, we observed that acute ethanol administration significantly reduced CAT and SOD activity in the hippocampus and increased CAT activity in the erythrocytes of rats. Chronic ethanol administration significantly reduced CAT and GSH$\mathrm{Px}$ activities in the hippocampus of rats. In rat erythrocytes, we observed a decrease in CAT and GSH-Px, activity, despite an increase in SOD activity. The different results caused by acute or chronic ethanol administration on the antioxidant enzyme activities probably occur due to the fact that in acute treatment rats were sacrificed $1 \mathrm{~h}$ after the administration of ethanol, when ethanol levels were high, while in chronic treatment rats were killed $12 \mathrm{~h}$ after the last injection, suggesting an effect that was promoted by secondary metabolites, and not by ethanol itself.

Although we cannot precisely establish the mechanisms by which an increase in CAT activity in erythrocytes was detected following ethanol acute administration, in addition to the increase in SOD activity in erythrocytes, caused by ethanol chronic administration, it is possible that this occurred due to a higher stimulation of enzyme synthesis through gene transcription, as a compensatory effect for the increased generation of free radicals provoked by ethanol. Previous data have shown that antioxidant enzymes may respond to oxidative stress by increasing their activity in order to reduce damages [37-39]. It is important to point out that enzymes investigated in this study seem to have a different response to ROS depending on the tissue investigated [40].

Our results suggest that acute and chronic ethanol administration induces oxidative stress, since it provoked lipoperoxidation as well as modified antioxidant enzyme activities in the rat hippocampus and blood, allowing us to verify the possible antioxidant effects of mate tea. Results showed that acute and chronic mate tea administration prevented the increase in TBARS, caused by acute and chronic ethanol administration in the hippocampus and plasma of rats.

With regard to antioxidant enzyme activity, results demonstrate that acute mate tea administration prevented the decrease in CAT and SOD activities in the rat hippocampus, caused by acute ethanol administration, although it was not capable of preventing the increase in CAT activity in rat erythrocytes, caused by acute ethanol administration. In addition, chronic mate tea administration prevented the reduction in CAT activity in the hippocampus and erythrocytes of rats, as well as preventing the reduction in GSH-Px activity in the hippocampus and erythrocytes and, finally, the increase in SOD activity in rat erythrocytes.

Our results corroborate previously data found in the literature $[13,20,27,41,42]$ showing the antioxidant properties of mate tea, where acute and chronic mate tea administration was found to prevent lipoperoxidation as well as prevent the modifications in antioxidant enzymes activities caused by ethanol in the hippocampus and blood of rats.

Miranda et al. demonstrated that mate tea increases DNA resistance against $\mathrm{H}_{2} \mathrm{O}_{2}$-induced damage [13], while other authors have observed a decrease in lipoperoxidation in the plasma and liver of rats, after mate tea consumption [27]. Yerba mate was shown to inhibit the progression of 


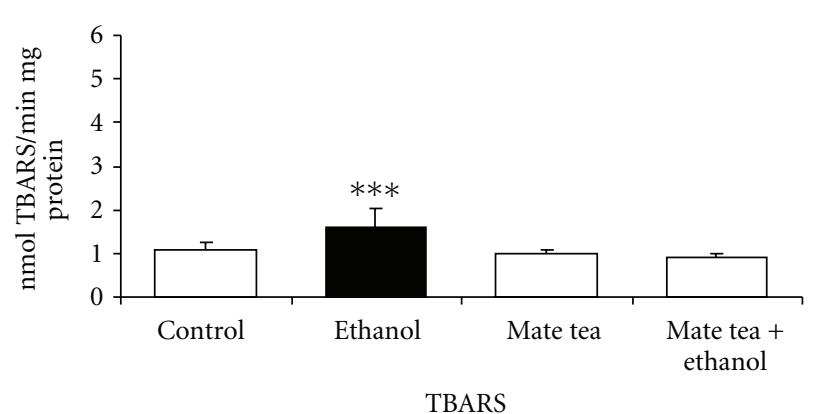

(a)

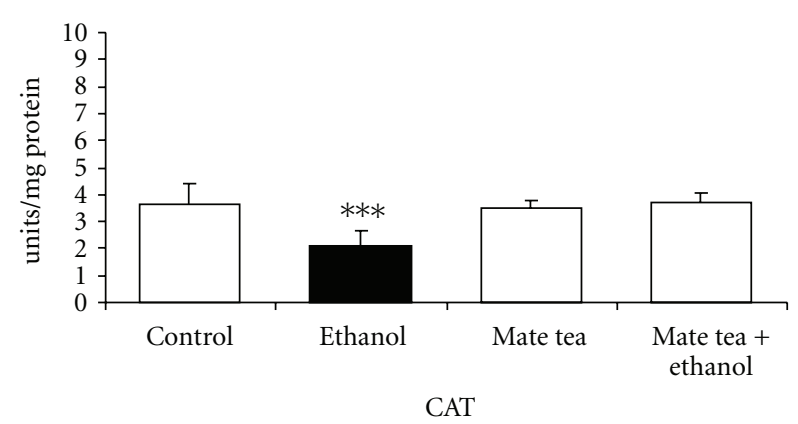

(c)

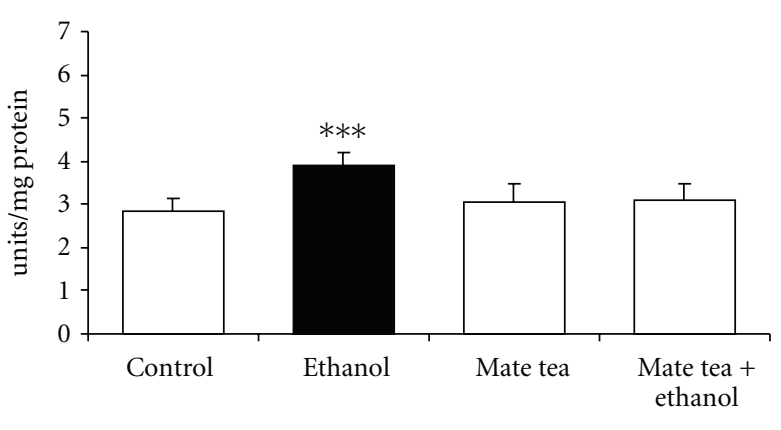

SOD

(b)

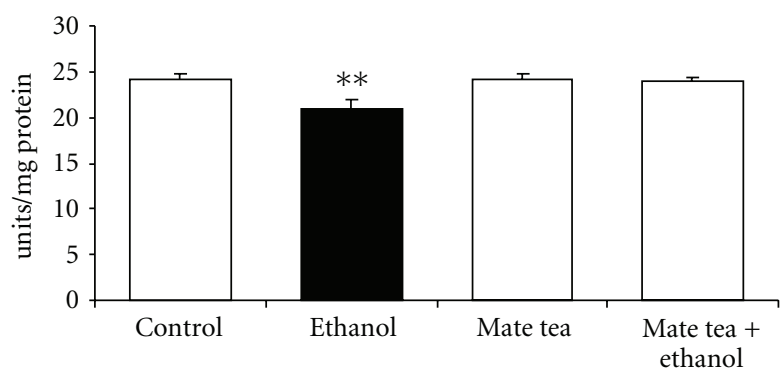

GSH-Px

FIGURE 4: Effects of chronic administration of ethanol, mate tea, and mate tea plus ethanol on thiobarbituric acid reactive substances (TBA-RSs) (a), on superoxide dismutase (b), catalase (c), and glutathione peroxidase (d) activities in rat blood. Data are mean \pm SD for 5 independent experiments (animals) performed in duplicate. ${ }^{* *} P<0.01$; ${ }^{* * *} P<0.001$ compared to control group (Duncan multiple-range test). One superoxide dismutase (SOD) unit is defined as the amount of SOD necessary to inhibit $50 \%$ of pyrogallol autoxidation. One catalase (CAT) unit is defined as $1 \mu \mathrm{mol}$ of $\mathrm{H}_{2} \mathrm{O}_{2}$ consumed per minute. One glutathione peroxidase (GSH-Px) unit is defined as $1 \mu \mathrm{mol}$ of NADPH consumed per minute.

atherosclerosis in cholesterol-fed rabbits, although it did not decrease the serum cholesterol or aortic TBARS and antioxidant enzymes [20]. The plasma concentration and tissue distribution of antioxidant compounds of a hydroethanolic extract of Ilex paraguariensis, before and after enzymatic hydrolysis, were accessed in rats. Both extracts presented high antioxidant activity and phenolic content. Rats given the hydrolyzed extract showed increased plasma antioxidant activity and higher plasma levels of caffeic acid. However, the hydrolyzed extract of Ilex paraguariensis did not altered skin and brain antioxidant activity in rats, 20 minutes after administration, suggesting that antioxidant compounds in the extract were not effectively distributed to these tissues or that the time to reach measurable concentrations was different from that in the sample collection [43].

Studies that involve yerba mate antioxidant effects in humans are still limited. In a study with healthy adults, a lower susceptibility of plasma and LDL-c to lipid peroxidation was found associated with a higher antioxidant capacity after acute ingestion of a mate infusion [41]. In another survey, healthy young women received $5 \mathrm{~g}$ of instant mate tea in $500 \mathrm{~mL}$ of water for a week and results showed that acute and prolonged consumption of mate tea resulted in a significant reduction in TBARS levels, in parallel to a significant increase in plasma resistance to peroxidation by
$\mathrm{Cu}^{2+}$. The gene expression of the antioxidant enzymes SOD, GSH-Px, and CAT also increased [42].

Mate tea potential was also tested on oxidative stress biomarkers and LDL oxidisability in normolipidaemic (NL) and hyperlipidaemic (HL) subjects. Chronic treatment with mate tea for 60 days $(2.5 \mathrm{~g}$ of instant mate tea to $200 \mathrm{~mL}$ of cold water) resulted in the marked increase in SOD activity in erythrocytes and serum total antioxidant status for both groups. Moreover, the lag time of copper-induced LDL peroxidation, a measure of resistance to oxidation, increased $53 \%$ and $69 \%$ for the NL and HL groups, respectively, after mate tea ingestion. The serum TBARS levels were significantly reduced in the HL group after treatment. On the other hand, GSH-Px activity and diene production $(\mathrm{nmol} / \mathrm{min} / \mathrm{mg}$ LDL) did not reach statistical significance for either group after supplementation [44].

There is growing evidence that oxidative stress may play an important role in the pathogenesis of Alzheimer's disease, Parkinson disease, and Amyotrophic lateral sclerosis, since the brain, which consumes large amounts of oxygen, is particularly vulnerable to oxidative damage [45]. Evidence also shows that nutritionally derived sources of brain-accessible antioxidants may provide an approach to slow the onset and progression of neurodegenerative disorders [46]. However, one possible limitation of the neuroprotective strategy 
(including antioxidant administration) might be consequent to the fact that when neurologic symptoms occur, a certain amount of neuronal death has already occurred. Thus, the neuroprotective agents (including antioxidants) can, at best, only rescue the surviving neurons, an effect that might not be sufficient to attenuate the neurologic symptomology. It is, therefore, important to start therapeutic intervention at an early stage in the disease process, suggesting that dietary habits may exert influence on the progression of neurodegenerative disorders [45]. Thus, mate tea intake might be an alternative to delay or prevent neurological disease, since our results showed that it provides antioxidant protection in CNS tissue.

In summary, in the present study we demonstrate that acute and chronic mate tea administration prevented the alterations in some parameters of oxidative stress in the hippocampus and blood of rats, caused by the in vivo administration of ethanol. This suggests that mate tea may have a high antioxidant capacity, probably due to its bioactive components and that mate tea ingestion could prevent oxidative stress-related disease. However, further studies are necessary to evaluate whether mate tea could be useful as a potential adjuvant therapy to neurologic patients.

\section{Abbreviations}

$\begin{array}{ll}\text { CAT: } & \text { Catalase } \\ \text { CNS: } & \text { Central nervous system } \\ \text { GSH-Px: } & \text { Glutathione peroxidase } \\ \mathrm{H}_{2} \mathrm{O}_{2}: & \text { Hydrogen peroxide } \\ \mathrm{MDA}: & \text { Malondialdehyde } \\ \mathrm{NADPH}: & \text { Nicotinamide adenine dinucleotide } \\ & \text { phosphate } \\ \mathrm{NTCD}: & \text { Nontransmissible chronic disease } \\ \mathrm{O}_{2}: & \text { Oxygen } \\ \text { ROS: } & \text { Reactive oxygen species } \\ \text { SOD: } & \text { Superoxide dismutase }\end{array}$

TBARS: Thiobarbituric acid-reactive substances.

\section{Acknowledgments}

The authors would like to thank Conselho Nacional de Desenvolvimento Científico e Tecnológico (CNPq-Brazil) and Universidade Regional de Blumenau by financial support.

\section{References}

[1] B. Uttara, A. V. Singh, P. Zamboni, and R. T. Mahajan, "Oxidative stress and neurodegenerative diseases: a review of upstream and downstream antioxidant therapeutic options," Current Neuropharmacology, vol. 7, no. 1, pp. 65-74, 2009.

[2] A. Catalá, "Lipid peroxidation of membrane phospholipids generates hydroxy-alkenals and oxidized phospholipids active in physiological and/or pathological conditions," Chemistry and Physics of Lipids, vol. 157, no. 1, pp. 1-11, 2009.

[3] G. Ulrich-Merzenich, H. Zeitler, H. Vetter, and K. Kraft, "Synergy research: vitamins and secondary plant components in the maintenance of the redox-homeostasis and in cell signaling," Phytomedicine, vol. 16, no. 1, pp. 2-16, 2009.
[4] F. Cacciapuoti, "Oxidative stress such as basic reaction of many among human diseases and ageing," Trends in Medicine, vol. 10, no. 4, pp. 191-197, 2010.

[5] M. Baron, A. P. Kudin, and W. S. Kunz, "Mitochondrial dysfunction in neurodegenerative disorders," Biochemical Society Transactions, vol. 35, no. 5, pp. 1228-1231, 2007.

[6] B. Halliwell, "Oxidative stress and neurodegeneration: where are we now?" Journal of Neurochemistry, vol. 97, no. 6, pp. 1634-1658, 2006.

[7] B. Halliwell and J. M. Gutteridge, "Free Radicals in Biology and Medicine," Free Radical Biology and Medicine, vol. 1, pp. 331-332, 2007.

[8] Y. A. Barnett and C. M. King, "An investigation of antioxidant status, DNA repair capacity and mutation as a function of age in humans," Mutation Research-DNAging Genetic Instability and Aging, vol. 338, no. 1-6, pp. 115-128, 1995.

[9] T. Finkel and N. J. Holbrook, "Oxidants, oxidative stress and the biology of ageing," Nature, vol. 408, no. 6809, pp. 239-247, 2000.

[10] W. Dröge, "Oxidative stress and ageing: is ageing a cysteine deficiency syndrome?" Philosophical Transactions of the Royal Society B, vol. 360, no. 1464, pp. 2355-2372, 2005.

[11] L. Gil, W. Siems, B. Mazurek et al., "Age-associated analysis of oxidative stress parameters in human plasma and erythrocytes," Free Radical Research, vol. 40, no. 5, pp. 495-505, 2006.

[12] A. Augustyniak, E. Waszkiewicz, and E. Skrzydlewska, "Preventive action of green tea from changes in the liver antioxidant abilities of different aged rats intoxicated with ethanol," Nutrition, vol. 21, no. 9, pp. 925-932, 2005.

[13] D. D. C. Miranda, D. P. Arçari, J. Pedrazzoli et al., "Protective effects of mate tea (Ilex paraguariensis) on $\mathrm{H}_{2} \mathrm{O}_{2}$-induced DNA damage and DNA repair in mice," Mutagenesis, vol. 23, no. 4, pp. 261-265, 2008.

[14] A. Kasdallah-Grissa, A. Nakbi, N. Koubaa et al., "Dietary virgin olive oil protects against lipid peroxidation and improves antioxidant status in the liver of rats chronically exposed to ethanol," Nutrition Research, vol. 28, no. 7, pp. 472-479, 2008.

[15] H. Sies, W. Stahl, and A. Sevanian, "Nutritional, dietary and postprandial oxidative stress," Journal of Nutrition, vol. 135, no. 5, pp. 96-972, 2005.

[16] S. Lim, H. Won, Y. Kim et al., "Antioxidant enzymes induced by repeated intake of excess energy in the form of high-fat, high-carbohydrate meals are not sufficient to block oxidative stress in healthy lean individuals," British Journal of Nutrition, vol. 106, no. 10, pp. 1544-1551, 2011.

[17] E. M. Yubero-Serrano, N. Delgado-Casado, J. Delgado-Lista et al., "Postprandial antioxidant effect of the Mediterranean diet supplemented with coenzyme $\mathrm{Q}_{10}$ in elderly men and women," Age, vol. 33, pp. 579-590, 2011.

[18] R. H. Liu, "Potential synergy of phytochemicals in cancer prevention: mechanism of action," Journal of Nutrition, vol. 134, supplement 12, pp. 3479S-3485S, 2004.

[19] A. E. I. Camargo, D. A. E. Daguer, and D. S. Barbosa, "Green tea exerts antioxidant action in vitro and its consumption increases total serum antioxidant potential in normal and dyslipidemic subjects," Nutrition Research, vol. 26, no. 12, pp. 626-631, 2006.

[20] A. L. Mosimann, D. Wilhelm-Filho, and E. L. da Silva, "Aqueous extract of Ilex paraguariensis attenuates the progression of atherosclerosis in cholesterol-fed rabbits," BioFactors, vol. 26, no. 1, pp. 59-70, 2006.

[21] D. H. M. Bastos, D. M. Oliveira, R. L. T. Matsumoto, P. O. Carvalho, and M. L. Ribeiro, "Yerba maté: pharmacological 
properties, research and biotechnology," Medicinal and Aromatic Plant Science and Biotechnology, vol. 1, pp. 37-46, 2007.

[22] C. Manach, A. Scalbert, C. Morand, C. Rémésy, and L. Jiménez, "Polyphenols: food sources and bioavailability," American Journal of Clinical Nutrition, vol. 79, no. 5, pp. 727-747, 2004.

[23] C. I. Heck and E. G. de Mejia, "Yerba mate tea (Ilex paraguariensis): a comprehensive review on chemistry, health implications, and technological considerations," Journal of Food Science, vol. 72, no. 9, pp. R138-R151, 2007.

[24] N. Bracesco, A. G. Sanchez, V. Contreras, T. Menini, and A. Gugliucci, "Recent advances on Ilex paraguariensis research: minireview," Journal of Ethnopharmacology, vol. 136, pp. 378384, 2011.

[25] F. Bosch-Morell, L. Flohé, N. Marín, and F. J. Romero, "4Hydroxynonenal inhibits glutathione peroxidase: protection by glutathione," Free Radical Biology and Medicine, vol. 26, no. 11-12, pp. 1383-1387, 1999.

[26] E. Albano, P. Clot, A. Comoglio, M. U. Dianzani, and A. Tomasi, "Free radical activation of acetaldehyde and its role in protein alkylation," FEBS Letters, vol. 348, no. 1, pp. 65-69, 1994.

[27] F. Martins, A. J. Suzan, S. M. Cerutti et al., "Consumption of mate tea (Ilex paraguariensis) decreases the oxidation of unsaturated fatty acids in mouse liver," British Journal of Nutrition, vol. 101, no. 4, pp. 527-532, 2009.

[28] H. Ohkawa, N. Ohishi, and K. Yagi, "Assay for lipid peroxides in animal tissues by thiobarbituric acid reaction," Analytical Biochemistry, vol. 95, no. 2, pp. 351-358, 1979.

[29] H. Aebi, "Catalase in vitro," Methods in Enzymology, vol. 105, pp. 121-126, 1984.

[30] A. Wendel, "Glutathione peroxidase," Methods in Enzymology, vol. 77, pp. 325-333, 1981.

[31] S. Marklund, Handbook for Oxygen Radical Research, CRC Press, Boca Raton, Fla, USA, 1985.

[32] O. H. Lowry, N. J. Rosebrough, A. L. Farr, and R. J. Randall, "Protein measurement with the Folin phenol reagent," The Journal of biological chemistry, vol. 193, no. 1, pp. 265-275, 1951.

[33] P. Van't Veer, M. C. Jansen, M. Klerk, and F. J. Kok, "Fruits and vegetables in the prevention of cancer and cardiovascular disease," Public Health Nutrition, vol. 3, no. 1, pp. 103-107, 2000.

[34] J. M. Genkinger, E. A. Platz, S. C. Hoffman, G. W. Comstock, and K. J. Helzlsouer, "Fruit, vegetable, and antioxidant intake and all-cause, cancer, and cardiovascular disease mortality in a community-dwelling population in Washington County, Maryland," American Journal of Epidemiology, vol. 160, no. 12, pp. 1223-1233, 2004.

[35] T. J. Key, "Fruit and vegetables and cancer risk," British Journal of Cancer, vol. 104, no. 1, pp. 6-11, 2011.

[36] B. Halliwell, "Antioxidants in human health and disease," Annual Review of Nutrition, vol. 16, pp. 33-50, 1996.

[37] M. Travacio and S. llesuy, "Antioxidant enzymes and their modification under oxidative stress conditions," Free Radical Research Latin America, vol. 48, no. 1-2, pp. 9-13, 1996.

[38] A. T. S. Wyse, E. L. Streck, P. Worm, A. Wajner, F. Ritter, and C. A. Netto, "Preconditioning prevents the inhibition of $\mathrm{NA}^{+}, \mathrm{K}^{+}$ATPase activity after brain ischemia," Neurochemical Research, vol. 25, no. 7, pp. 971-975, 2000.

[39] D. Delwing, C. S. Bavaresco, F. A. Chiarani et al., "In vivo and in vitro effects of proline on some parameters of oxidative stress in rat brain," Brain Research, vol. 991, no. 1-2, pp. 180 186, 2003.
[40] I. Ceballos-Picot, J. M. Trivier, A. Nicole, P. M. Sinet, and M. Thevenin, "Age-correlated modifications of copperzinc superoxide dismutase and glutathione-related enzyme activities in human erythrocytes," Clinical Chemistry, vol. 38, no. 1, pp. 66-70, 1992.

[41] E. L. da Silva, T. J. C. Neiva, M. Shirai, J. Terao, and D. S. P. Abdalla, "Acute ingestion of yerba mate infusion (Ilex paraguariensis) inhibits plasma and lipoprotein oxidation," Food Research International, vol. 41, no. 10, pp. 973-979, 2008.

[42] R. L. T. Matsumoto, D. H. M. Bastos, S. Mendonça et al., "Effects of Maté tea (Ilex paraguariensis) ingestion on mRNA expression of antioxidant enzymes, lipid peroxidation, and total antioxidant status in healthy young women," Journal of Agricultural and Food Chemistry, vol. 57, no. 5, pp. 1775-1780, 2009.

[43] D. P. Rivelli, R. L. Almeida, C. D. Ropke, and S. B. M. Barros, "Hydrolysis influence on phytochemical composition, antioxidant activity, plasma concentration, and tissue distribution of hydroethanolic Ilex paraguariensis extract components," Journal of Agricultural and Food Chemistry, vol. 59, no. 16, pp. 8901-8907, 2011.

[44] D. P. Arçari, V. B. Porto, E. R. V. Rodrigues et al., "Effect of mate tea (Ilex paraguariensis) supplementation on oxidative stress biomarkers and LDL oxidisability in normo- and hyperlipidaemic humans," Journal of Functional Foods, vol. 3, no. 3, pp. 190-197, 2011.

[45] E. Esposito, D. Rotilio, V. Di Matteo, C. Di Giulio, M. Cacchio, and S. Algeri, "A review of specific dietary antioxidants and the effects on biochemical mechanisms related to neurodegenerative processes," Neurobiology of Aging, vol. 23, no. 5, pp. 719$735,2002$.

[46] D. A. Butterfield, A. Castegna, C. B. Pocernich, J. Drake, G. Scapagnini, and V. Calabrese, "Nutritional approaches to combat oxidative stress in Alzheimer's disease," Journal of Nutritional Biochemistry, vol. 13, no. 8, pp. 444-461, 2002. 


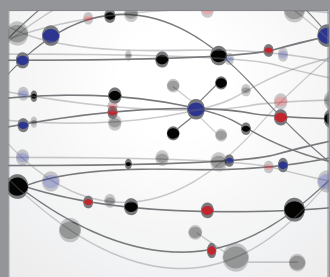

The Scientific World Journal
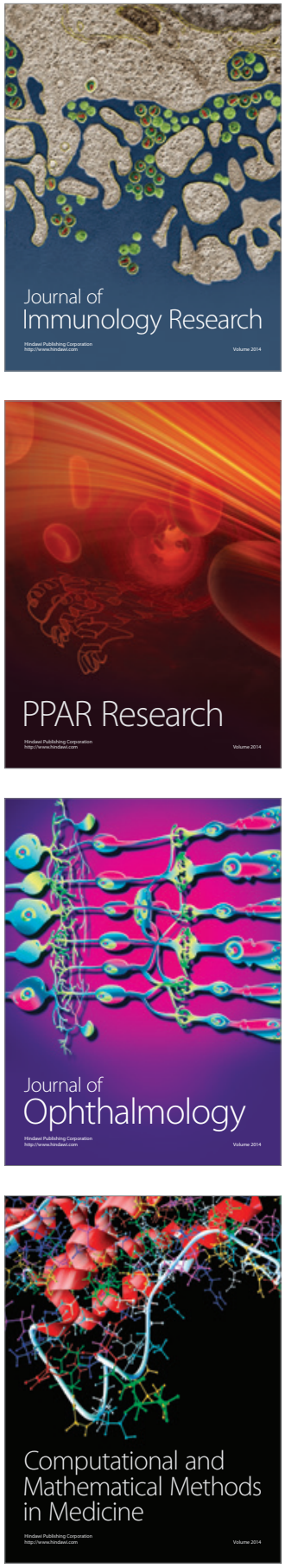

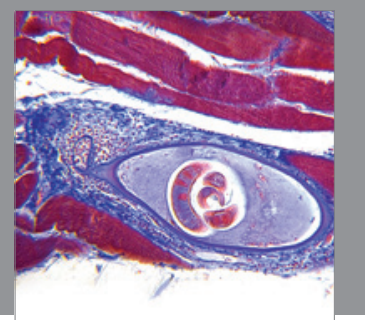

Gastroenterology

Research and Practice
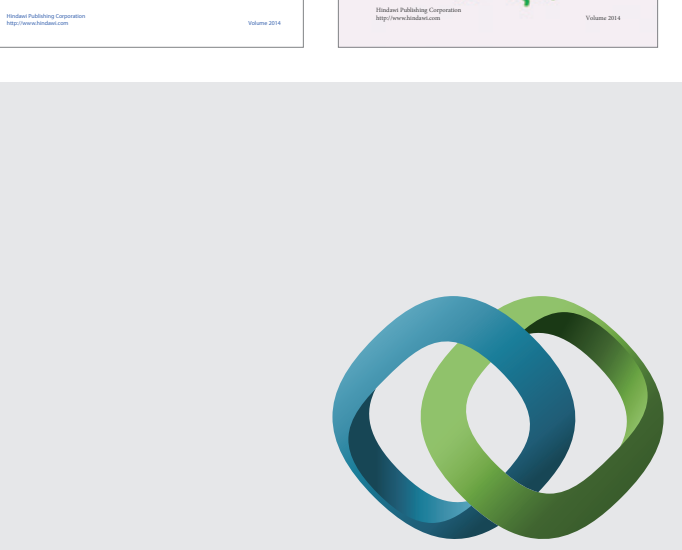

\section{Hindawi}

Submit your manuscripts at

http://www.hindawi.com
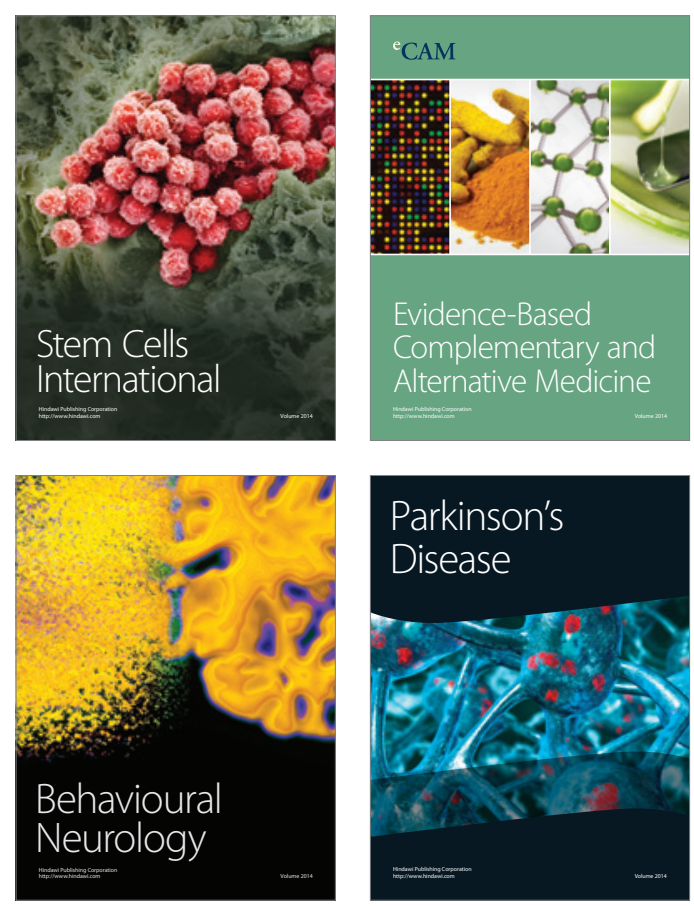

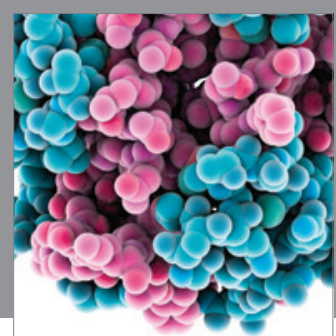

Journal of
Diabetes Research

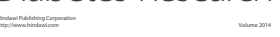

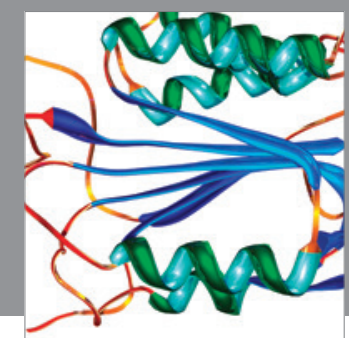

Disease Markers
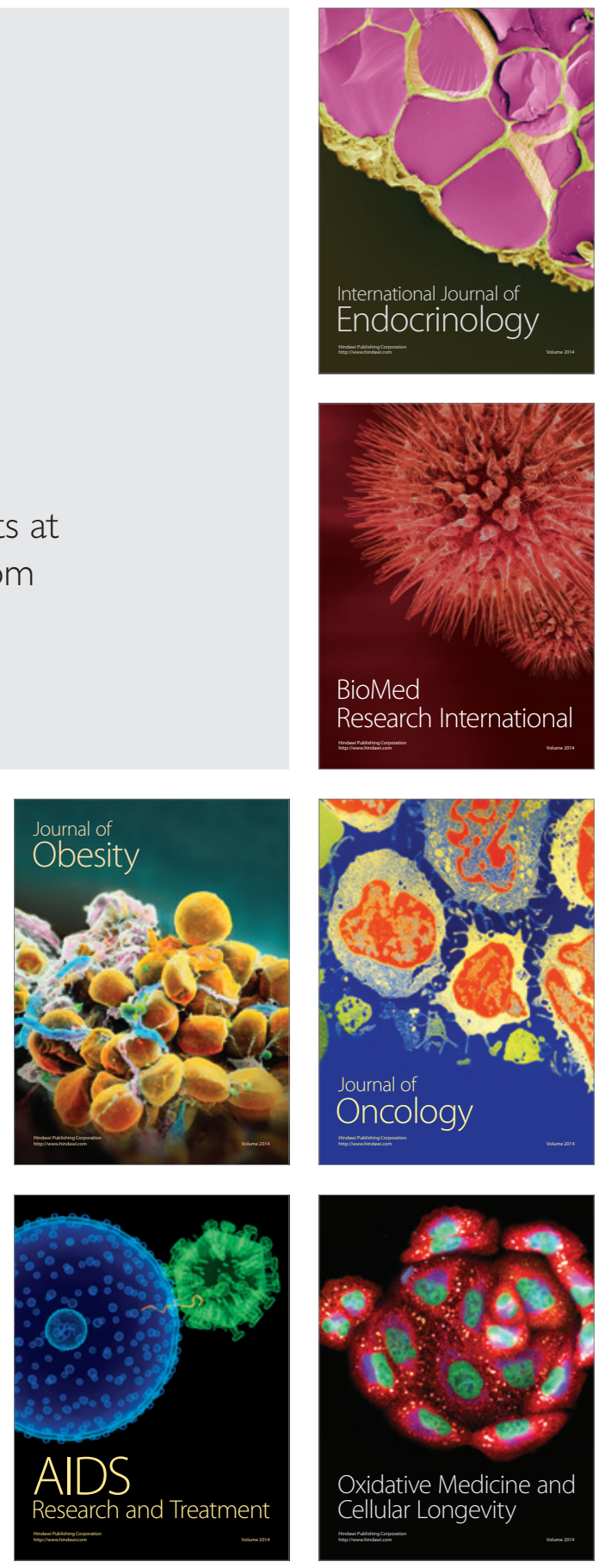